\title{
Statistical Validation of Exit Examination Results
}

Larry W. Spradley, (E-mail: spradleylw@hal.lamar.edu), Lamar University Brenda D. Spradley, (E-mail: spradleybd@hal.lamar.edu), Lamar University

\begin{abstract}
In an effort to validate teaching effectiveness within the College of Business at Lamar University a standardized achievement test, the Business Major Field Test, offered by the Educational Testing Service of Princeton, NJ, was administered to a relatively large sample (69) of the class of graduating seniors in the spring semester of 2001. The overall results placed the average of Lamar's graduating business majors at approximately the $70^{\text {th }}$ percentile among the institutions taking the exam. Considering the popularly held opinion that the entering freshman class at Lamar ranks closer to the $40^{\text {th }}$ percentile of those taking the SAT, these results seemed almost too good to be true. This study is designed to describe our testing methods, validate or invalidate this "valueadded" result, and discuss our future plans.
\end{abstract}

\section{Introduction}

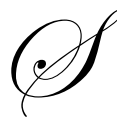

tandardized achievement testing has become an integral element in the evaluation of Texas public schools. A recent national survey conducted by the polling team of Peter Hart and Robert Teeter, who also administer The Wall Street Journal/NBC poll, found that " $76 \%$ [of the respondents] support a policy that would require every student in grades three through eight to be tested annually in reading and math, using tests developed by each state, but $78 \%$ also want state test results compared using a "nationally standardized test." 1 Although not currently mandated for Texas colleges and Universities, standardized testing, nevertheless, provides a way of measuring success for those institutions, which claim to be "teaching" institutions. In an effort to demonstrate teaching effectiveness within the College of Business at Lamar University a standardized achievement test, the Business Major Field Test offered by the Educational Testing Service of Princeton, NJ, was administered to a relatively large sample (69) of the class of graduating Business majors in the spring semester of 2001. According to the ETS:

"The Business Test is intended to:

- Measure students' academic achievement in the multidisciplinary subject matter representative of undergraduate business education.

- $\quad$ Provide information to students regarding their level of achievement.

- $\quad$ Provide information to faculties regarding the achievement of their students; information that can be used by the institution to assess their performance relative to their specific mission and objectives.

- $\quad$ Provide information to facilitate development of appropriate goals and educational programs, and to enhance the accountability of undergraduate education.",2

The overall results placed the average of Lamar's graduating business majors at approximately the $70^{\text {th }}$ percentile among the institutions taking the exam. Considering the popularly held opinion that the entering freshman class at Lamar ranks closer to the $40^{\text {th }}$ percentile of those taking the SAT, these results seemed almost too good to be true. This study is designed to describe our testing methods, validate or invalidate this "value-added" result, and discuss our future plans.

\footnotetext{
${ }^{1}$ http://www.ets.org/aboutets/issues6.html

${ }^{2}$ http://www.ets.org/hea/mft/ubusiness.html
} 
This study will have two primary emphases: First, will be a statistical validation of the sampling procedure's results already obtained in the spring of 2001 and the second emphasis will be an attempt to replicate the results in future semesters eliminating the sources of bias which are found in the thorough statistical study of the results already obtained.

To study the current results one assumption will be made: There is a significant correlation between entering aptitude and exiting achievement. As a convenient proxy for entering aptitude, this study will use SAT results and, of course, achievement will be measured through the Business Major Field Test. Correlation Analysis will determine whether this is a valid assumption in this case. Then, the graduation GPA's of the students taking the examination will be analyzed to determine whether they are truly representative of the GPA's of the entire class. The SAT scores of entering freshmen at Lamar University during the 1996-97 and 1997-98 terms will be obtained from the University database to substantiate the popularly perceived level of entering aptitude. Then the average SAT of the business students, who took the exit exam will be determined to test whether these students' aptitude is statistically similar to the entering class as a whole. In addition, information must be obtained from the SAT concerning the percentiles of all students taking the SAT during the years of study.

The second emphasis will be realized by giving the Business Major Field Test to graduating business majors in the future. If inherent biases are discovered in this study, there will be an attempt to eliminate the sources of the bias when the exit exam is given to the graduating business majors in the spring of 2002. If funding is obtained the tests can be given to all graduating business majors.

\section{Validation Of Assumptions}

The entering SAT score for each individual who took the exam was obtained from the official University information system. Of the 69 individuals who took the ETS Major Field Test, 16 did not have an officially recorded SAT score. Among these 16 individuals 2 had an ACT score recorded, but the rest did not have any recorded entrance aptitude indicator. Consequently these sixteen individuals where not included in the test correlation study. Four of the individuals had taken the SAT on multiple occasions and the last SAT score was the score used in this study. In all four cases the individuals had scored higher on their last test than on any previous tries. The improvements in the scores of these seven individuals are remarkable. The improvements ranged from 80 to 190 with an average improvement of 137.5 points. This improvement possibly reflects the role that attitude plays in taking a standardized test such as this. Many students take the SAT with an "I don't care" attitude and then realize later that their score does make a difference and they retake the exam with a higher level of motivation. There also is the possibility that some of these students who perform poorly on their first try are motivated to take an SAT prep course which might significantly improve their performance. The correlation study produced the following results: The correlation coefficient between the ETS scores and the SAT scores was computed to be .662, which is statistically significant at the .000 level (using SPSS as in most all calculations herein); thus supporting the original assumption that there is a correlation between entering aptitude and exiting achievement.

Since the graduating GPA's were also available for the students who took the ETS exam, an additional study was performed on the relationship between the SAT scores, the graduation GPA's and the ETS scores. A statistically significant regression model for predicting ETS scores was obtained using both the SAT's and the GPA's with an R of .677, but when the stepwise regression method of analysis was used it was revealed that the GPA's did not statistically significantly reduce the standard error of the estimate from that model using the SAT scores only. Consequently, the study indicates that the most statistically significant correlation exists between the entering SAT scores and the exiting ETS scores. This correlation between the entering SAT's and the exiting ETS scores is much higher than the correlation between the entering SAT's and the exiting GPA's (.487) or between the exiting GPA's and the exiting ETS scores (.448).

This high correlation between the two standardized tests may be more of a reflection of the standardized nature of the two tests, rather than a true measure of the correlation between entering aptitude and exiting achievement. One would think that since the overall GPA is a measure of achievement, it would have been more highly correlated to the ETS achievement measure than this study revealed. 
The ETS field test was administered to only a sample of graduating business majors. This sampling procedure was felt necessary for several reasons. Since the students had to give extracurricular time in which to take the exam, it was felt that if the test was mandatory some students might give less than their best in an effort to get out of the test as soon as possible. In an attempt to counter the bias of only the best students volunteering to take the exam, extra points were awarded in the capstone course to all students who would volunteer to take the exam. Since the exit results are based on this sample, statistical tests were run to validate the sample of students who took the exam. First the average GPA of all graduating business majors was obtained from the University database. The one sample t-test revealed no statistically significant difference between the average GPA of the sample group and the average GPA of the graduating senior business majors.

Secondly, the average SAT scores for the entering class of business majors in the fall semester of 1996 was obtained and there was no statistically significant difference between this score and the average GPA of the sample group. This last comparison has several problems, however. It might be assumed that the average GPA of the senior class at any University would be higher than the average GPA of the entering freshman class because of natural attrition. Also, the University database records the average GPA of all the students who were declared business majors in the fall of 1996. Between the fall of 1996 and the spring of 2001 this population may have major changes in identity as students change their majors both into and out of business. To illustrate this problem, the average GPA of the sample group was statistically significantly higher than the average of the freshmen business majors of the fall of 1997 (but not the fall, 1996 class).

In summary, no statistically significant evidence was found to invalidate the sample group as an unbiased sample of Lamar's graduating class of business majors. Consequently there is no reason to question the percentile evaluation among the participating colleges and universities.

The observation that initially motivated this study, the "value-added" results, proved to be unverifiable. This conclusion became obvious when the population of schools taking the SAT was compared to the population of schools taking the ETS field tests. Whereas the SAT enjoys almost universal acceptance, (approximately 3,185,000 individuals took the SAT I and SAT II in 2000-2001) $)^{3}$ the ETS field tests are being used by only a select group of approximately 380 colleges and universities. Unfortunately this select group is not a random sample of the SAT population, but reflects a noticeable absence of major institutions, which have reputations of outstanding academic excellence. Comparing the two percentiles would be like comparing "apples and oranges." In order to validly study the "value-added" concept, one would have to obtain the percentile rankings of the SAT scores from only those students who enrolled in the colleges and Universities who participated in the ETS exit exams. This information would be almost impossible to obtain because students taking the SAT quite often have their test scores sent to multiple schools. However, the following observations were made. The average entering SAT scores for the 53 students who took the exit exam was 975.85 . According to ETS an individual score of 970 would place a 2001 college-bound student in the $40^{\text {th }}$ percentile and a score of 980 would place the individual in the $42^{\text {nd }}$ percentile. As alluded to earlier, the average SAT scores for entering freshmen business majors in the fall of 1996 was only 929. Although this score in even lower than the average of the students who took the exit exam it is not statistically significantly lower.

\section{Conclusions}

Even though only a sample of graduating seniors at Lamar University took the ETS Business Major Field Test, there was no statistical evidence that this sample would bias or invalidate the conclusion that the graduating class average is close to the seventieth percentile of all the schools participating in the study. Because of the difference in the participating institutions forming the SAT population and the ETS population no conclusions can be validly made concerning the "value-added" results when comparing SAT percentiles and ETS percentiles, even though there is a statistically significant correlation between the SAT scores and the ETS scores. Finally, one should be very aware of the still limited population of institutions participating in the ETS major field tests and not make inferences to a more universal population.

\footnotetext{
${ }^{3}$ http://www.ets.org/aboutets/volumes.html
} 
In the spring semester of 2002, Lamar University will again administer the ETS Major Field Test to a sample of our graduating business majors. This study has not discovered evidence of any bias in the sampling procedure and the exit exam will be administered in a manner consistent with the procedure utilized in the spring of 2001.

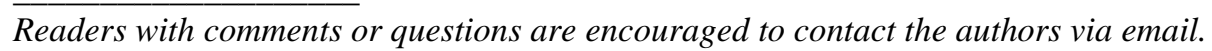

Notes 